\title{
Estimation of serum matrix metalloproteinases among patients of oral squamous cell carcinoma
}

\author{
Nakhshab Choudhry', Sana Sarmad², \\ Noor ul Ain Waheed ${ }^{3}$, Aamir Jamal Gondal ${ }^{4}$
}

\begin{abstract}
Objective: To estimate the serum levels of matrix metalloproteinases in oral squamous cell carcinoma patients and in healthy subjects.

Methods: In this observational study, biopsy diagnosed oral squamous cell carcinoma patients $(n=38)$ were recruited from Mayo Hospital, Lahore during 2016 to 2017. Age and gender matched Controls $(n=38)$ were also included. Venous blood sample of each participant was drawn, serum separated and the levels of matrix metalloproteinases were measured by multiplex ELISA.

Results: Serum levels of MMP-1, -8, $-10,-12$ and -13 in OSCC patients showed statistically significant increase as compared to control group ( $<<0.01)$. The MMP-12 predicted the presence of OSCC with highest AUC of $0.836(95 \% \mathrm{Cl}[0.733$ to 0.911$])$ for sensitivity and specificity of $80 \%$ and $78.9 \%$, respectively for a cut-off value of $16.13 \mathrm{pg} / \mathrm{ml}$.

Conclusions: MMP-12 has been found to have significant sensitivity and specificity to qualify as a diagnostic biomarker.
\end{abstract}

KEYWORDS: Squamous cell carcinoma, Matrix metalloproteinase, Enzyme-linked immunosorbent assay.

How to cite this:

doi: https://doi.org/doi.org/10.12669/pjms.35.1.68

Choudhry N, Sarmad S, Waheed NA, Gondal AJ. Estimation of serum matrix metalloproteinases among patients of oral squamous cell carcinoma. Pak J Med Sci. 2019;35(1):252-256. doi: https://doi.org/doi.org/10.12669/pjms.35.1.68

This is an Open Access article distributed under the terms of the Creative Commons Attribution License (http://creativecommons.org/licenses/by/3.0), which permits unrestricted use, distribution, and reproduction in any medium, provided the original work is properly cited.

\section{INTRODUCTION}

Oral Squamous Cell Carcinoma (OSCC) has the highest incidence among oral cancers globally.

1. Prof. Dr. Nakhshab Choudhry, PhD.

Department of Biochemistry,

2. Dr. Sana Sarmad, MPhil.

Department of Biochemistry,

Rashid Latif Medical College, Lahore, Pakistan.

3. Dr. Noor ul Ain Waheed, MPhil.

Department of Biochemistry,

4. Mr. Aamir Jamal Gondal, MPhil.

Department of Biomedical Sciences,

1,3,4: King Edward Medical University,

Lahore, Pakistan.

Correspondence:

Prof. Dr. Nakhshab Choudhry, PhD.

Chairman, Department of Biochemistry,

King Edward Medical University,

Neela Gumband,

Lahore, Pakistan.

E-mail: drnbchoudhry@gmail.com

* Received for Publication:

September 15, 2018

* Revision Received:

* Revision Accepted: *
November 28, 2018

December 5, 2018
Despite recent advances in OSCC therapy, its 5 -year survival rate is only as high as $55 \%{ }^{1}$ Multiple risk factors have been linked with OSCC, including such specific factors as tobacco- and alcohol-use (substance-use). Regardless of this strong association, a considerable fraction of patients develop OSCC without exposure to them, underlining the role of genetic predisposition and oncogenic viruses. $^{2}$

Matrix metalloproteinases (MMPs) are special class of proteases that are categorized in five groups as per their substrate specificity: collagenases (MMP-1, -8 and -13), gelatinases (MMP-2 and -9), stromelysins (MMP-3, -10, and -11), matrilysins (MMP-7) and membrane-type (MMP-14 to -17, -24 \& -25). More than 25 distinct MMP genes have been identified in humans to date. ${ }^{3}$

Generally, there is a relationship between proteases level and cancer dissemination. Increased expression of MMPs such as MMP-1, -2, -3, -7, -9, $-13,-14$ are associated with cancer progression, i.e. 
poor prognosis, poor cancer cell differentiation, invasive cancer stage with low patient survival and metastatic spread to distant sites. ${ }^{4}$

Potential of OSCC to metastasize rests on its ability to break through the basement membrane, to penetrate the surrounding tissues and vascular structures and to bring about new vessel formation for tumor dissemination. Invasive potential of OSCC is positively attributed to the ability of neoplastic cells to deploy MMPs that are synthesized by the patient's stromal cells. Many recent studies have reported the impact of MMPs in the advancement of OSCC either directly altering the extracellular environment or indirectly through initiation of vascular regression., ${ }^{5,6}$ Currently employed clinical tools for the detection of OSCC like biopsy, exfoliative cytology and vital tissue staining are generally applicable to a select group of patients and have distinct limitations. ${ }^{7}$

Little data are available for a biomarker that could aid in the detection of primary OSCC at nondetectable cancer tissue or precursor stage. Certain biomarkers may serve threefold advantage; for detection at an earlier stage, as prognostic marker, and a therapeutic target. ${ }^{8}$ MMPs are one of those potential markers that can theoretically serve all of these purposes. Determination of MMP levels in various tissue fluids has been suggested as easy, quick and noninvasive tool for primary diagnosis and subsequent prognostic monitoring of diseases. ${ }^{9}$

Some previously published studies indicated that certain multiplex panels of biomarkers have significant (85\%) diagnostic accuracy in small study cohorts of OSCC patients..$^{10}$ Many of these studies concluded that a wider analytic panel would contribute significantly to clinical benefits. However, early diagnosis may warrant avenues for better clinical management.

No study is currently available in Pakistani population concerning the measurement of serum MMPs levels. In present study, we measured the levels of MMP-1, $-2,-3,-7,-8,-9,-10,-12$, and -13 in OSCC patients and healthy subjects.

\section{METHODS}

In this observational study thirty-eight biopsy positive OSCC patients aged 30-71 years of either gender were recruited from the Oral and Maxillofacial Surgery Department, Mayo Hospital, Lahore, Pakistan from July to December, 2016 with prior informed consent. Non-probability purposive sampling technique was used. Patients receiving chemotherapy/radiotherapy or having rheumatoid arthritis, diabetic foot or acute myocardial infarction were excluded. Age and gender matched thirtyeight healthy subjects aged from 30 to 70 years of either gender were also included as control group. Demographic and clinical findings of both the groups were recorded in the prescribed proforma. Ethical approval of the study was obtained from the Institutional Review Board of King Edward Medical University Lahore Pakistan (KEMU).

Five $\mathrm{ml}$ venous blood sample from each subject of two groups was drawn in serum separator tubes (Vacutainer SST, Becton-Dickinson, USA), allowed to clot for 10-15 minutes and then centrifuged at $1700 \mathrm{~g}$ for four minutes. Clear serum supernatant thus obtained was separated in labeled microfuge tubes and stored at $-80 \pm 5^{\circ} \mathrm{C}$. Before assay the serums were thawed and brought to room temperature till the estimation of serum MMPs.

MMP 1-13 levels were measured by multiples ELISA using Bio-Plex Pro ${ }^{\mathrm{TM}}$ Human MMP Panel kit (9-Plex \#171-AM001M, Bio-Rad, USA). The assay reactions were performed as per the instructions of the manufacturer and results read on Multi-Analyte Bio-Plex ${ }^{\circledR}$ MAGPIX ${ }^{\mathrm{TM}}$ Multiplex Reader (Bio-Rad, USA).

Statistical Analysis: Statistical analysis was performed by MedCalc v15.8 statistical software. The difference of age, gender, smoking and substanceuse between OSCC group and control group was analyzed by student $t$ test and chi square test of independence. MMP levels were expressed as median and Interquartile Range (IQR). Mann-Whitney U test was used to compare the MMP levels between two groups. Statistical significance was assumed at $\mathrm{P} \leq$ 0.05. Receiver Operating Characteristic (ROC) curve analysis was performed to determine the area under the curve (AUC) with 95\% confidence interval (95\% CI) for sensitivity and specificity of the statistically significant MMPs of both groups to evaluate the predictive value of OSCC.

\section{RESULTS}

There was no statistical difference in terms of age, gender, smoking and substance use in the two groups (Table-I). Of the twenty seven smokers, $96 \%$ $(n=26)$ were males and $4 \%(n=1)$ were female $(4 \%)$. Among substance users $(n=40)$, twenty seven $(67.5$ $\%)$ were males and thirteen (32.5) were females. However, $55 \%(\mathrm{n}=22)$ used betel leaf/ tobacco / nuts, $37.5 \%(\mathrm{n}=15)$ were tobacco sniffers while $7.5 \%$ were mix users.

The OSCC lesion was well differentiated in $51 \%(n=20)$, moderately differentiated in $41 \%$ 
Biomarker of squamous cell carcinoma

Table-I: Demographic Characteristics.

\begin{tabular}{lcccc}
\hline Characteristic & Type & Patients $(n=38)^{\text {Control }(n=38)}$ & $P_{\text {value }}^{a}$ \\
\hline Age (year) ${ }^{c}$ & & $50.9 \pm 9.4$ & $50.8 \pm 10.3$ & 0.952 \\
Gender (n) & Male & 26 & 23 & $0.472^{\mathrm{b}}$ \\
& Female & 12 & 15 & $0.810^{\mathrm{b}}$ \\
Smoking (n) & Yes & 14 & 13 & $0.645^{\mathrm{b}}$ \\
& No & 24 & 25 & 19 \\
Substance use (n) & Yes & 21 & 19 & \\
& No & 17 & & \\
Lesion Differentiation & Well & 20 & 16 & \\
\end{tabular}

${ }^{a} \mathrm{p}$ value calculated by $\mathrm{t}$-test or chi square; ${ }^{\mathrm{b}}$ statistical significance; $\mathrm{p}<0.05 ;{ }^{\mathrm{c}}$ Mean $\pm \mathrm{SD}$.

$(n=16)$ and poorly differentiated in $8 \%(n=2)$. The predominant site of OSCC lesion was tongue $(40 \%)$.

Median and Interquartile range (IQR) were calculated for each of the nine MMP levels (pg/ml) for OSCC and control groups. The plasma levels of MMP-1 ( $p=0.002)$, MMP-8 ( $p=0.001)$, MMP$10(p=0.001), M M P-12(p=0.002)$ and MMP-13 ( $p$ $=0.006)$ showed statistically significant increase in OSCC patients as compared to controls. The values of serum MMPs in OSCC patients and healthy subjects are given Table-II.

ROC curve analysis showed that almost all the MMPs had AUC more than 0.500 (Table-III). Among the MMPs having statistically significant increase in their values for OSCC group as compared to control group, the MMP-12 predicted the presence of OSCC with highest AUC of 0.836 (95\% CI [0.733 to 0.911]) for sensitivity and specificity of $80.0 \%$ and $78.9 \%$, respectively (Fig.1).

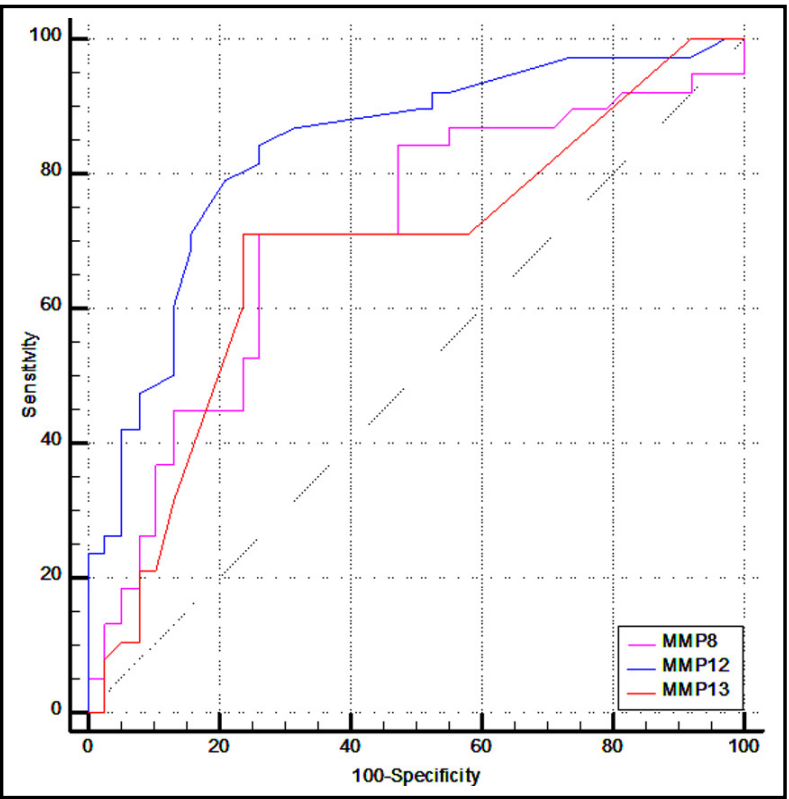

Fig.1: ROC curve analysis of MMPs.

Table-II: MMP Levels (pg/ml) in OSCC and Control Groups.

\begin{tabular}{lccc}
\hline MMP Type & OSCC Group Median (IQR) & Control Group Median (IQR) & P value $^{a}$ \\
\hline MMP-1 & $565.8(325.0$ to 1199.9$)$ & $350.5(258.0$ to 740.1$)$ & 0.002 \\
MMP-2 & $2345.9(1861.2$ to 3686.0$)$ & $4006.4(2569.1$ to 6317.6$)$ & 0.002 \\
MMP-3 & $858.3(313.8$ to 1713.3$)$ & $1038.7(447.4$ to 1879.0$)$ & 0.55 \\
MMP-7 & $263.9(165.6$ to 468.4$)$ & $173.9(122.0$ to 338.2$)$ & 0.13 \\
MMP-8 & $927.5(421.7$ to 2219.1$)$ & $325.4(152.3$ to 911.8$)$ & 0.001 \\
MMP-9 & $6491.8(2794.4$ to 11004.8$)$ & $4138.6(2213.0$ to 12829.4$)$ & 0.42 \\
MMP-10 & $77.0(21.9$ to 368.8$)$ & $27.0(12.2$ to 65.4$)$ & 0.001 \\
MMP-12 & $47.2(18.6$ to 141.0$)$ & $10.7(6.7$ to 16.1$)$ & 0.002 \\
MMP-13 & $5.0(1.5$ to 9.1$)$ & $1.8(1.5$ to 3.2$)$ & 0.006 \\
\hline
\end{tabular}

${ }^{a}$ Mann-Whitney U-test, $\mathrm{p} \leq 0.05$ was considered statistically significant. 
Nakhshab Choudhry et al.

Table-III: ROC Curve Analysis for MMPs.

\begin{tabular}{lccccc}
\hline \multirow{2}{*}{ Marker } & \multicolumn{5}{c}{ ROC parameters } \\
\cline { 2 - 6 } & AUC & $95 \%$ CI & Sensitivity (\%) & Specificity (\%) & Cut- off value (pg/ml) \\
\hline MMP-1 & 0.642 & 0.524 to 0.749 & 71.1 & 55.3 & $>362$ \\
MMP-2 & 0.704 & 0.588 to 0.803 & 65.8 & 73.7 & $\leq 2726.15$ \\
MMP-3 & 0.539 & $0.421-0.655$ & 28.9 & 86.8 & $\leq 313.8$ \\
MMP-7 & 0.600 & $0.482-0.711$ & 73.7 & 55.3 & $>183.91$ \\
MMP-8 & 0.706 & 0.591 to 0.805 & 71.1 & 73.7 & $>659.93$ \\
MMP-9 & 0.554 & $0.436-0.668$ & 55.3 & 65.8 & $>5929.88$ \\
MMP-10 & 0.721 & 0.606 to 0.817 & 36.8 & 100 & $>160.45$ \\
MMP-12 & 0.836 & 0.733 to 0.911 & 80.0 & 78.9 & $>16.13$ \\
MMP-13 & 0.681 & $0.564-0.783$ & 71.1 & 76.3 & $>3.24$ \\
\hline
\end{tabular}

\section{DISCUSSION}

Histologically, squamous type OSCC is the most prevalent cancer of oral cavity causing about 8590\% cancer burden in Pakistani population. ${ }^{11}$ The pursuit of a biomarker for the timely and precise detection of OSCC is ever increasing. However, different biomarkers have been tested and remained in use despite different limitations.

In this study we measured levels of $9 \mathrm{MMPs}$ in age and gender matched OSCC patients and controls. Individually except MMP-3, -7 and -9 all others showed difference in their median serum levels between the two groups. However, the median serum level of MMP-2 was statistically higher in controls as compared to OSCC patients thereby giving idea about some feedback regulation.

The role of higher MMP-2 expression was found linked to metastatic potential and poor survival in OSCC patients as observed in archival tissue immunohistochemistry of 30 OSCC patients and 10 controls. The expression of MMP transcripts was not measured by qPCR and did not measure the plasma levels. ${ }^{12}$ Another study reported that the immunohistochemical expression analysis of MMP-2 supported the prognostic aggressiveness of head and neck tumors, ${ }^{13}$ however no measurement of plasma levels found. A study by Kamata et al. showed that cell invasion drastically increased with elevated expression of MMP-2. ${ }^{14}$ However, our results regarding MMP-2 seem to be different, whereby the plasma levels were not increased, from previous researches which reported increased in expression. Zhang et al. showed higher levels of MMP-1 in OSCC associated fibroblasts when compared to normal fibroblasts. ${ }^{15}$ Similarly, Ha et al. linked invasiveness of OSCC to enhanced levels of MMP-1 and $-10 .{ }^{16}$
A study by Ahmad et al. on MMP-7, -8 and -9 in oral and cutaneous squamous cell cancers showed MMP-7 expression to be elevated at the invasion front and MMP-9 mildly expressed. However, contrary to our results MMP- 8 was not found in the OSCC but was present, along with MMP 9, in pericancerous inflammatory cells. ${ }^{17}$ A study by Korpi et al. stated a positive association of MMP-8 with patient survival thus hypothesizing a protective role of MMP- $8 .{ }^{18}$ In accordance with our findings, Stott-Miller et al. observed highly elevated, yet not statistically significant, levels of MMP-1 and -3 in saliva of patients with OSCC compared to healthy controls. ${ }^{19}$

Makinen et al. associated MMP-13 with invasion depth and poor prognosis. ${ }^{20}$ Of all the nine MMPs under investigation in the current study, a single proteinase (MMP-12) was identified with high confidence $(\mathrm{p}<0.05)$ and 4 proteinases (MMP-2, -8 , -10 and -12 ) showed a significant expression change between cancer patients and healthy controls.

Yen et al reported MMP-1 and MMP-10 as potential oral cancer marker by using AUCs of relative gene expression as $0.715,0.727$ and 0.513 for MMP-1, MMP-10 and MMP-12, respectively. ${ }^{21}$ While in our findings, MMP-12 predicted the presence of OSCC with highest AUC of 0.836 (95\% CI [0.733 to 0.911]) for sensitivity and specificity of $80.0 \%$ and $78.9 \%$, respectively in serum.

Using ROC curve analysis, we have shown for the first time in Pakistan that a biomarker panel measuring serum MMPs has the ability of reliably differentiating normal healthy individuals from patients of biopsy positive OSCC. These findings suggest that this novel biomarker has great potential for clinical use in both diagnosis and management. 
Limitations of the study and Future Directions: A smaller sample size from a single hospital was used. A larger and diverse sample along with the evaluation of genetic expression of each MMP would provide better insight for diagnostic, prognostic and therapeutic roles.

\section{CONCLUSION}

It is clearly seen from the current data that out of all the MMPs used in this study, only MMP-12 has been found to have significant sensitivity and specificity to be recommended as a diagnostic biomarker.

Grant Support \& Financial Disclosures: The project was funded by the King Edward Medical University, Lahore.

Conflict of Interest: There is no conflict of interest.

\section{REFERENCES}

1. Siegel RL, Miller KD, Jemal A. Cancer statistics, 2017. CA Cancer J Clin. 2017;67(1):7-30. doi: 10.3322/caac.21387

2. Abbasi SA, Baig RM, Shah A, Ahmad MN. The role of human papillomavirus in head \& neck squamous cell carcinoma. Gomal J Med Sci. 2017;15(2)

3. Ager EI, Kozin SV, Kirkpatrick ND, Seano G, Kodack DP, Askoxylakis V, et al. Blockade of MMP14 activity in murine breast carcinomas: implications for macrophages, vessels, and radiotherapy. J Natl Cancer Inst. 2015;107(4). doi: 10.1093/jnci/djv017

4. Pang L, Wang D-W, Zhang N, Xu D-H, Meng X-W. Elevated serum levels of MMP-11 correlate with poor prognosis in colon cancer patients. Cancer Biomark. 2016;16(4):599-607. doi: 10.3233/CBM-160601

5. Brown GT, Murray GI. Current mechanistic insights into the roles of matrix metalloproteinases in tumour invasion and metastasis. J Pathol. 2015;237(3):273-281. doi: $10.1002 /$ path.4586

6. Da Silva SD, Morand GB, Alobaid FA, Hier MP, Mlynarek AM, Alaoui-Jamali MA, et al. Epithelial-mesenchymal transition (EMT) markers have prognostic impact in multiple primary oral squamous cell carcinoma. Clin Exp Metastasis. 2015;32(1):55-63. doi: 10.1007/s10585-014-9690-1

7. Yakob M, Fuentes L, Wang MB, Abemayor E, Wong DT. Salivary biomarkers for detection of oral squamous cell carcinoma: current state \& recent advances. Curr Oral Health Rep. 2014;1(2):133-141. doi: 10.1007/s40496-014-0014-y

8. Li W, Liu M, Su Y, Zhou X, Liu Y, Zhang X. The Janusfaced roles of Krüppel-like factor 4 in oral squamous cell carcinoma cells. Oncotarget. 2015;6(42):44480. doi: 10.18632/ oncotarget.6256

9. Mishev G, Deliverska E, Hlushchuk R, Velinov N, Aebersold D, Weinstein F, et al. Prognostic value of matrix metalloproteinases in oral squamous cell carcinoma. Biotechnol Biotechnol Equip. 2014;28(6):1138-1149. doi: 10.1080/13102818.2014.967510

10. Hathaway B, Landsittel DP, Gooding W, Whiteside TL, Grandis JR, Siegfried JM, et al. Multiplexed analysis of serum cytokines as biomarkers in squamous cell carcinoma of the head and neck patients. Laryngoscope. 2005;115(3):522-527. doi: 10.1097/01.mlg.0000157850.16649.b8
11. Rahamthulla SU, Priya PV, Hussain SJ, Nasyam FA, Akifuddin S, Srinivas VS. Effectiveness of the supraomohyoid neck dissection in clinically N0 neck patients with squamous cell carcinoma of buccal mucosa and gingivobuccal sulcus. J Int Soc Prev Community Dent. 2015;5(2):131. doi: 10.4103/2231-0762.155740

12. Shrestha B, Bajracharya D, Byatnal AA, Kamath A, Radhakrishnan R. May High MMP-2 and TIMP-2 Expressions Increase or Decrease the Aggressivity of Oral Cancer? Pathol Oncol Res. 2017;23(1):197-206. doi: 10.1007/ s12253-016-0149-3

13. Ruokolainen H, Pääkkö $P$, Turpeenniemi-Hujanen T. Tissue and circulating immunoreactive protein for MMP-2 and TIMP-2 in head and neck squamous cell carcinoma - tissue immunoreactivity predicts aggressive clinical course. Mod Pathol. 2006;19(2):208

14. Kamata Y, Sumida T, Kobayashi $Y$, Ishikawa A, Kumamaru W, Mori Y. Introduction of ID2 Enhances Invasiveness in ID2-null Oral Squamous Cell Carcinoma Cells via the SNAIL Axis. Cancer Genomics Proteomics. 2016;13(6):493497. doi: $10.21873 / \operatorname{cgp} .20012$

15. Zhang Z, Tao D, Zhang P, Liu X, Zhang Y, Cheng J, et al. Hyaluronan synthase 2 expressed by cancer-associated fibroblasts promotes oral cancer invasion. J Exp Clin Cancer Res. 2016;35(1):181. doi: 10.1186/s13046-016-0458-0

16. Ha NH, Woo BH, Ha ES, Choi JI, Kim SJ, Park BS, et al. Prolonged and repetitive exposure to Porphyromonas gingivalis increases aggressiveness of oral cancer cells by promoting acquisition of cancer stem cell properties. Tumour Biol. 2015;36(12):9947-9960. doi: 10.1007/s13277015-3764-9

17. Omar AAH, Haglund C, Virolainen S, Häyry V, Atula T, Kontio R, et al. MMP-7, MMP-8, and MMP-9 in oral and cutaneous squamous cell carcinomas. Oral Surg Oral Med Oral Pathol Oral Radiol. 2015;119(4):459-467. doi: 10.1016/j. oooo.2014.12.019

18. Korpi JT, Kervinen V, Mäklin H, Väänänen A, Lahtinen M, Läärä E, et al. Collagenase-2 (matrix metalloproteinase-8) plays a protective role in tongue cancer. $\mathrm{Br} \mathrm{J}$ Cancer. 2008;98(4):766-775. doi: 10.1038/sj.bjc.6604239

19. Stott-Miller M, Houck JR, Lohavanichbutr P, Méndez E, Upton MP, Futran ND, et al. Tumor and salivary matrix metalloproteinase levels are strong diagnostic markers of oral squamous cell carcinoma. Cancer Epidemiol Biomarkers Prev. 2011;20(12):2628-2636. doi: 10.1158/1055-9965

20. Mäkinen LK, Häyry V, Atula T, Haglund C, KeskiSäntti H, Leivo I, et al. Prognostic significance of matrix metalloproteinase-2,-8,-9, and-13 in oral tongue cancer. J Oral Pathol Med. 2012;41(5):394-399. doi: 10.1111/j.16000714.2011.01110.x

21. Yen C-Y, Chen C-H, Chang C-H, Tseng H-F, Liu S-Y, Chuang L-Y, et al. Matrix metalloproteinases (MMP) 1 and MMP10 but not MMP12 are potential oral cancer markers. Biomarkers. 2009;14(4):244-249.

\section{Authors Contribution:}

NC: Conceived, designed and final approval of manuscript.

SS \& NAW: Data collection, performance of tests and manuscript writing.

AJG: Statistical analysis, review and editing of manuscript. 